\title{
EVALUATION OF LOWER URINARY TRACT SYMPTOMS (LUTS): SEVERITY SCORE AND SYMPTOM ASSOCIATION
}

\author{
Pradhan $T^{1^{*}}$, Thapa $B D^{1}$, Basnet $T^{1}$, Basnet $P^{1}$, Rimal $S P^{1}$, Regmi $M C^{1}$
}

\section{Affiliation}

1. Associate Professor Department of Obstetrics and Gynaecology, B. P. Koirala Institute of Health Sciences.

\section{ARTICLE INFO}

Article History

$$
\begin{aligned}
& \text { Received : } 19 \text { January, } 2019 \\
& \text { Accepted : } 2 \text { July, } 2019 \\
& \text { Published : } 31 \text { August, } 2019
\end{aligned}
$$

(C) Authors retain copyright and grant the journal right of first publication with the work simultaneously licensed under Creative Commons Attribution License CC - BY 4.0 that allows others to share the work with an acknowledgment of the work's authorship and initial publication in this journal.

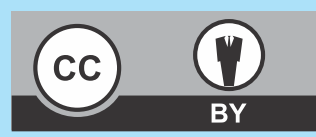

ORA 113

\section{DOI: http://dx.doi.org/10.3126/bjhs.v4i2.25435}

\author{
* Corresponding Author \\ Dr. Tarun Pradhan \\ Associate Professor \\ Department of Obstetrics and Gynaecology \\ B. P. Koirala Institute of Health Sciences \\ E-mail ID:dr_tarun802@hotmail.com \\ ORCID ID : https://orcid.org/0000-0001-6446-7986
}

\section{Citation}

Pradhan T, Thapa BD, Basnet T, Basnet P, Rimal SP, Regmi MC. Evaluation of Lower Urinary Tract Symptoms (LUTS): Severity Score And Symptom Association. BJHS 2019;4(2)9: 684-687.

\section{ABSTRACT}

\section{Introduction}

Lower urinary tract symptoms (LUTS) is a group of symptoms relating to stages of micturation such as storage symptoms, voiding dysfunction and post micturation dysfunction. Overactive bladder symptom score (OABSS) is a questionnaires with scores which helps in evaluating the severity of symptoms.

\section{Objectives}

To find the incidence of women visiting with LUTS_and to evaluate storage symptoms in LUTS (urgency, urge incontinence, frequency) using OABSS (overactive bladder symptom score) questionnaires.

\section{Methodology}

This is a prospective study done from February 2016 to February 2017. Patients visiting Department of Obstetrics and Gynaecology with lower urinary tract symptoms (LUTS) were enrolled in the study after informed consent. Patients were assessed for types of LUTS and data were filled in the performa. If patients had urgency, urge incontinence, increased day time frequency, then the patients were explained and asked overactive bladder symptom score questionnaire (OABSS) and noted. Patients were then examined for pelvic floor dysfunction and neurological abnormalities for identifying association with the symptoms. Statistical analysis was done using SPSS 11.5.

\section{Results}

Fifty-seven patients were enrolled with lower urinary tract symptoms (LUTS) during study period. Forty-six patients had overactive bladder symptoms (OABS). LUTS were found in age ranging from 21 to 80 years.

Majority of patients visiting out-patient department with LUTS were found to have urgency, urge incontinence, increased day time frequency, nocturia.

Patients with urgency and urge incontinence showed significant correlation with increasing likert score of OABSS $(p<0.05)$. But the increased day time frequency did not show any correlation with increasing score. The score showed significant correlation with combination of symptoms (urgency, urge incontinence and increased frequency) than patients presenting with single symptom.

\section{Conclusion}

Diagnosis of LUTS with valid assessment tools and treatment benefits patients with chronic urinary symptoms and also helps clinicians to further re-assess the treatment.

\section{KEYWORDS}

Lower urinary tract symptoms; overactive bladder; urgency; urge incontinence. 


\section{INTRODUCTION}

Symptoms are the subjective indicator of a disease or change in condition as perceived by the patient, carer or partner and may lead patients to seek help from health care professionals. Symptoms may either be volunteered or described during the patient interview. The term lower urinary tract symptoms are defined from the individual's perspective who is usually, but not necessarily, a patient visiting for check up. Symptoms are either volunteered by, or elicited from, the individual or may be described by the individual's caregiver. ${ }^{1}$ Lower urinary tract symptom (LUTS) encompasses a wide range of symptoms, categorized by the International Continence Society (ICS) as storage, voiding, and post-micturation symptoms. The term storage symptoms are (increased daytime urinary frequency, urgency, nocturia, urinary urge incontinence), voiding symptoms are (slow stream, intermittency, hesitancy, straining) and postmicturition symptoms are (sensation of incomplete emptying, postmicturition dribble). ${ }^{1}$ The storage subset of LUTS includes overactive bladder (OAB) symptoms, which, according to the Standardization Subcommittee of the ICS, is a syndrome characterized by urinary urgency, usually with urinary daytime frequency and nocturia, in the absence of an underlying metabolic or pathological condition, and may or may not be accompanied by urgency incontinence., 2 Urgency is defined as a sudden compelling desire to pass urine, which is difficult to defer, while day time frequency is the complaint by a patient that they void too often during the day. Nocturia is the complaint that the individual has to wake at night one or more times to void. Urge urinary incontinence is the complaint of involuntary leakage accompanied by or immediately preceded by urgency, as frequent small losses between micturations or as a catastrophic leak with complete bladder emptying. ${ }^{1} \mathrm{OAB}$ is a chronic condition that imposes negative impact on patients health-related quality of life (HRQoL). Among the storage symptoms, urge incontinence has received the most attention, but urgency and increased daytime frequency also have a clinically significant impact on patients HRQoL., Traditionally, urinary frequency is considered the primary outcome measure for the evaluation of LUTS storage symptoms; however, urgency is now regarded as the pivotal symptom and is often the focus of investigations. ${ }^{5,6}$ Measurement of urinary urgency is challenging because of different ways the patients interpret their symptoms also because of its non-specific nature, its association with other storage symptoms like increased day time urinary frequency. ${ }^{7}$ LUTS are found to be prevalent among women. The prevalence of continent and incontinent $O A B$ is estimated to be $16.6 \%$ in the United States and 6 to $35 \%$ in Europe. ${ }^{4}$ This area of urinary dysfunctions are yet to be studied in large population in our region, thus the gravity of the morbidity is not properly understood.

Since $O A B$ is defined by subjective symptoms, rather than objective measures, the patient's perspective is important in managing $\mathrm{OAB}$. To understand the patient's perspective, several patient-reported outcome instruments are available and Overactive Bladder symptom score Questionnaire (OABSS) is one of the validated assessment tools.

The Overactive bladder symptom score (OABSS) by Blaivas quantifies all the aspects of $O A B$ and include graded response for storage dysfunction of LUTS. The higher the score, the worse are the symptoms. ${ }^{8}$

Pelvic organ prolapse (POP) and pelvic floor dysfunctions has been identified as reproductive health morbidities in Nepal. In Nepal, POP prevalence is estimated at $10 \%$ among women of reproductive age (between 15 and 49 years) and $24 \%$ among post-menopausal women between 45 and 49 years. ${ }^{9}$ ${ }^{10}$ LUTS is commonly found with pelvic organ prolapse among women in rural Nepal. Cystocele was found in advanced and symptomatic prolapse. ${ }^{11}$ The study was designed to know the number of women visiting hospital with Lower Urinary Tract Symptoms(LUTS), particularly $\mathrm{OAB}$ and to assess patients with symptoms of overactive bladder (OAB) like urgency, urge incontinence, frequency using OABSS (overactive bladder symptom score) questionnaires.

\section{METHODOLOGY}

This is a prospective study done from February 2016 to February 2017 after approval from institutional review committee (IRC) B. P. Koirala Institute of Health Sciences. Patients visiting outpatient clinic in Department of Obstetrics and Gynaecology with lower urinary tract symptoms (LUTS) were enrolled in the study after informed written consent. Patients were assessed for presenting with different lower urinary tract symptoms and filled in the performa. If patients had urgency, urge incontinence, increased day time frequency then the patients were explained about the Overactive bladder symptoms score questionnaires (OABSS) and the symptoms scores of Likert scale were noted in the performa. Patients were then examined for pelvic floor dysfunction, pelvic organ prolapse, stress urinary incontinence (SUI), neurological abnormalities for identifying association with the symptoms.

The number of cases collected were plotted in MS excel chart. Statistical analysis was done using SPSS 11.5. Mean, percentage, standard deviation were calculated for descriptive analysis and non-parametric test, T-test and oneway-Anova test were applied to find the association of severity of LUTS with scores of Likert scale from OABSS $(p<0.05)$. Chi-square test and pearsons correlation test was applied for finding relation of age, parity and menopausal status with the score from Likert scale. $(p<0.05)$

\section{RESULTS}

Among 16,288 patients visiting out patient's clinic with general gynaecology complaints, 57 came with lower urinary tract symptoms (LUTS) during the study period. The incidence was found to be $0.3 \%$. Forty-seven $(82.4 \%)$ patients had complaints of overactive bladder symptoms (OABS) such as urgency, urge incontinence, increased daytime frequency.

Thirty-seven patients were more than 35 year of age and none of the patients were below 20 year with mean (SD) of 47.49(13.46). Increasing age showed highly significant relation with increasing score in overactive bladder symptom score(OABSS). Majority of patients had less than 2 child 
births with mean (SD) of $3.07(2.14)$ but increasing parity showed significant relation with increasing likert scale. Menopause status didn't show any significant relation with Overactive bladder symptoms score in likert scale. (Table.1)

Table.1: Relation of demographic variables with score of Likert Scale.

$\begin{array}{llccc}\text { Variables } & \text { Number }(\mathrm{n}=5 \mathbf{7}) & \text { P value } & \text { Remark } \\ \text { Age } & <\mathbf{2 0} & \mathbf{0} & \mathbf{0 . 0 0 0} & \text { Significant } \\ & \mathbf{2 0 - 4 5} & \mathbf{2 0} & & \\ \text { Parity } & \geq \mathbf{4 5} & \mathbf{3 7} & & \\ \text { Menopause } & \leq 2 & 31 & 0.003 & \text { Significant } \\ & >3 & 26 & & \\ & \text { Yes } & 28 & 0.86 & \text { Not significant }\end{array}$

Out of 57 patients, majority of patients had symptoms of storage dysfunctions (Urgency, urge incontinence, increased day time frequency) along with Stress Urinary Incontinence (SUI) and nocturia. Presence of urge incontinence and stress urinary incontinence showed significant relation with increasing score in likert scale. Presence of other lower urinary tract symptoms (LUTS) did not show significant relation with likert scale.

\section{Table.2: LUTS in relation to increasing Likert score.}

$\begin{array}{lcccc}\text { LUTS } & \begin{array}{c}\text { Number of } \\ \text { pts(n=57) }\end{array} & \text { Mean } & P(<0.05) & \text { Remark } \\ \text { Urgency } & 45 & 19.29 & 0.07 & \text { Not significant } \\ \text { Urge Incontinence } & 32 & 20.63 & 0.001 & \text { Significant } \\ \text { Frequency } & 39 & 19.03 & 0.94 & \text { Not significant } \\ \text { Nocturia } & 30 & 19.47 & 0.43 & \text { Not significant } \\ \text { Hesitency } & 4 & 17.00 & 0.43 & \text { Not significant } \\ \text { Sensation of } & 17 & 18.47 & 0.61 & \text { Not significant } \\ \text { incomplete } & & & & \\ \text { evacuation Dribbling } & & & & \\ \text { Stress Urinary } & 8 & 18.63 & 0.83 & \text { Not significant } \\ \text { Incontinence } & 21 & 20.81 & 0.03 & \text { Significant } \\ \text { Urinary Retention } & 2 & 17 & 0.59 & \text { Not significant } \\ \text { Straining } & 7 & 20.29 & 0.49 & \text { Not significant }\end{array}$

Forty seven patients showed symptoms of urgency, urge incontinence and increased day time frequency either one or in combination. Increasing score in likert scale were significantly related with patients presenting with increasing combination of symptoms.

Among the patients with lower urinary tract symptoms when examined for pelvic organ prolapse, majority of patients were found to have anterior compartment defect however patients with apical prolapse showed significant relation with increasing likert scale.

Table.3: Relation of increasing number of OAB symptoms with Likert score

\begin{tabular}{|c|c|c|c|c|c|}
\hline OAB symptoms & Symptoms & $\begin{array}{c}\text { No of } \\
\text { pt }\end{array}$ & $\begin{array}{l}\text { Mean } \pm S D \\
\text { of score }\end{array}$ & $P$ value & Remarks \\
\hline 1. Urgency & Any one & 4 & $14.00 \pm 4.24$ & \multirow{4}{*}{0.017} & \multirow[t]{4}{*}{ Significant } \\
\hline 2. Urge & 2 of 3 & 17 & $17.47 \pm 5.31$ & & \\
\hline $\begin{array}{l}\text { incontinence } \\
\text { 3. Day time } \\
\text { frequency }\end{array}$ & $\begin{array}{c}\text { Presence } \\
\text { of all }\end{array}$ & 26 & $20.77 \pm 4.81$ & & \\
\hline Total & & 47 & $19.00 \pm 5.32$ & & \\
\hline
\end{tabular}

Table.4: Relation of POP with increasing Likert score.

\begin{tabular}{|c|c|c|c|c|}
\hline POP & Number (n) & Mean & P Value & Remark \\
\hline Apical prolapse & 8 & 22.44 & 0.02 & Significant \\
\hline \multicolumn{5}{|l|}{ Anterior } \\
\hline $\begin{array}{l}\text { Compartment } \\
\text { prolapse }\end{array}$ & 25 & 19.92 & 0.21 & Not significant \\
\hline \multicolumn{5}{|l|}{ Posterior } \\
\hline $\begin{array}{l}\text { Compartment } \\
\text { Prolapse }\end{array}$ & 8 & 20.2 & 50.47 & Not significant \\
\hline
\end{tabular}

\section{DISCUSSION}

The study showed increasing number of LUTS with increasing age with majority of storage symptoms may be due to associated increasing parity and pelvic organ prolapse. But as compared with other studies Lower urinary tract symptoms (LUTS) are commonly seen in women with high parity and advancing age similar to this study where there is significant association between parity, advancing age with high likert scale and none of the women were below 20 years of age but in contrast LUTS and urinary incontinence were found to be high in presumably healthy nulligravida and young patients with relatively low bother. ${ }^{12}$

Overactive bladder symptoms questionnaire (OABSS) used in this study showed increased score in likert scale when symptoms presented in more than one combination and urge incontinence showed significant association with increasing score. Similarly with other questionnaire on total urgency and frequency score (TUFS) and patient perception of intensity of urgency scale (PPIUS) score only focuses on urgency and frequency score system to assess storage LUTS, which concludes only urgency as most significant symptom addressing $\mathrm{OAB} .^{13}$

Similar overactive bladder symptom score focuses on a single symptom score that employs a self report questionnaire to quantify $O A B$ symptoms. The questionnaire was selected on day time frequency, night time frequency, urgency, urge incontinence. The overall score is sum of all four symptoms. The difference from our score is that the minimum and maximum score varies with the questionnaire unlike in our study the score is same for all questionnaire. ${ }^{14}$

In large scale, multi-national (Canada, Germany, Sweden, United Kingdom, Italy), population based, cross-sectional survey of women showed LUTS that define OAB to be $12.8 \%$ and $6.3 \%$ of the women were found to be with urge incontinence. Among LUTS, storage symptoms were 59.2\%, voiding dysfunction were found in $19.5 \%$ and $14.2 \%$ were found to be with post-micturation symptoms. Overall storage symptoms were reported more than voiding and post-micturation symptoms. ${ }^{15}$

Intensity of urgency associated with each urinary or incontinence episodes was also measured using patients perceptions of intensity of urgency scale (PPIUS) to assess the content validity, test re-test reliability and acclimation effect of PPIUS in overactive bladder (OABS) patients. The results demonstrated content validity based on qualitative interviews, and excellent test-retest reliability among stable 
patients. These findings support the use of the PPIUS as a reliable measure of urgency in both clinical trial and real life settings. ${ }^{16}$

Overactive Bladder Symptom Score was also correlated with voiding diary and urodynamic parameters like detrussor activity; maximal cystometric capacity was tested in patients with overactive bladder symptoms. Overactive Bladder Symptom Score was found to correlate well with both. Thus, was concluded that the OABSS could be helpful tool to diagnose severity of overactive bladder in absence of voiding diary or urodynamic apparatus. ${ }^{17}$

The understanding of symptoms of LUTS have been further elaborated with symptoms assessment accomplished with psychometrically validated patients reported outcomes (PRO) tools. As in this study we focused on storage symptoms of LUTS using overactive bladder symptoms score questionnaires (OABSS). This new tool has been introduced as Lower Urinary Tract Symptoms Score (LUTSS) questionnaire. It consisted of 14 questions on a 5 point scale scored from 0-4. Nine questions pertained to storage symptoms, 4 to voiding symptoms and 1 to bother. The total score ranged from 0-56, where higher score indicated worst symptoms. In contrast to OABSS, Lower urinary tract symptoms score doesn't consider urinary urgency to be an all or none phenomenon but rather the symptom that can be graded. ${ }^{18}$

LUTS are found to affect majority of adults age $>40$ years in China and prevalence increases with increasing age. LUTS are also associated with impaired quality of life and mental health but less than of the population seeks help for the symptoms which is similar to our population and therefore there is need to improve awareness and treatment of the conditions. ${ }^{19}$

\section{REFERENCES}

1. Abrams P, Cardozo L, Fall M, Griffiths D, Rosier P, Ulmsten $U$ et al. The standardisation of terminology of lower urinary tract function: report from the Standardisation Sub-committee of the International Continence Society. Neurourol Urodyn 2002; 21: 167-78. DOI: 10.1002/nau.10052.

2. Abrams P, Artibani W, Cardozo L, Dmochowski R, van Kerrebroeck P, Sand P. Reviewing the ICS 2002 terminology report: the ongoing debate. Neurourol Urodyn 2009; 28: 287. doi: $10.1002 /$ nau.20737

3. Stewart WF, Van Rooyen JB, Cundiff GW, Abrams P, Herzog AR, Corey R et al. Prevalence and burden of overactive bladder in the United States. World J Urol; 20: 327-36. PMID: 12811491

4. Coyne KS, Payne C, Bhattacharyya SK, Revicki DA, Thompson C, Corey R et al. The impact of urinary urgency and frequency on health related quality of life in overactive bladder: result from national community survey. Value Health; 7: 455-63.PMID: 15449637.

5. Starkman JS, Dmochowski RR. Urgency assessment in the evaluation in overactivebladder(OAB). NeurourolUrodyn. 2008;27(1):13-21.PMID:17671973.

6. Cardozo L, Hessdörfer E, Milani R, Arañó P, Dewilde L, Slack M. Solifenacin in the treatment of urgency and other symptom of overactive bladder: results from a randomized, double blind, placebo controlled, rising- dose trial. BJU Int.; 102(9):1120-7. PMID: 18990175

7. Freeman RM. How urgent is urgency? A review of current methods of assessments. Int Urogynecol J Pelvic Floor Dysfunct. 2005 Mar-Apr; 16(2):93-5. PMID: 15789143

8. Blaivas JG, Panagopoulos G, Weiss JP, Somaroo C: Validation of the overactive bladder symptom score. J Urol 2007; 178:543-547. PMID: 17570417. DOI: $10.1016 /$ j.juro.2007.03.133

9. UNFPA. Status of reproductive morbidities in Nepal, 2006. Kathmandu United Nations Popul Fund, www.advocacynet. org/modules/fck/upload /file/upa/Status of Reproductive Morbidities in Nepal.pdf (accessed 13 June 2013).

10. Gurung G, Rana A, Amatya A, Bista KD, Joshi AB, Sayami J. Pelvic organ prolapse in rural Nepalese women of reproductive age groups: what makes it so common? Nepal J Obstet Gynaecol 2008; 2: 35-41. DOI: https://doi.org/10.3126/njog.v2i2.1453

\section{CONCLUSION}

Lower Urinary Tract Symptoms, especially overactive bladder symptoms was found to be common presentation among LUTS. Overactive Bladder Symptoms Score showed significant correlation with overactive bladder symptoms, thus can be helpful in assessing severity.

\section{RECOMMENDATION}

Though the sample size was small, overactive bladder symptoms score correlated well with the OAB symptoms. Thus, Overactive Bladder Symptoms Score can be used as a tool to assess OAB symptoms severity both pre-treatment and post treatment evaluation. And also for practical use in clinical practices and research purposes.

\section{LIMITATION OF THE STUDY}

Lower Urinary Tract Symptoms was found to be common complaints yet unaddressed. OABSS was found to be significantly correlating with overactive bladder symptoms but still more sample would help in concrete statistical analysis.

\section{CONFLICT OF INTEREST}

None declared

\section{FINANCIAL DISCLOSURE}

None.

11. Lien YS, Chen GD, Ng SC. Prevalence of and risk factors for pelvic organ prolapse and lower urinary tract symptoms among women in rural Nepal. Int J Gynaecol Obstet.; 119(2):185-8. PMID: 22925819

12. Hendrikje M. K. van Breda, J. L. H. Ruud Bosch, Laetitia M. O. de Kort. Hidden prevalence of lower urinary tract symptoms in healthy nulligravid young women. Int Urogynecol J; 26:1637-1643.DOI 10.1007/s00192015-2754-1

13. Christopher R. Chapple, Marcus J. Drake, Philip Van Kerrebroeck, Linda Cardozo, Ted Drogendijk, Monique Klaver et al. Total urgency and frequency score as a measure of urgency and frequency in overactive bladder and storage lower urinary tract symptoms. BJU Int; 113: 696-703. DOI:10.1111/bju.12555roo

14. Homma Y, Yoshida M, Seki N, et al: Symptom assessment tool for overactive bladder syndrome--overactive bladder symptom score. Urology 2006; 68:318-323. PMID: 16904444.

15. Irwin, D.R., Milsom, I., Hunskaar, S. et al. Population-based survey of urinary incontinence, overactive bladder, and other lower urinary tract symptoms in five countries: results of the EPIC study. Eur Urol; 50: 1306-1315. PMID: 17049716.

16. Sherilyn M Notte, Thomas $S$ Marshall, Misun Lee, Zalmai Hakimi, Isaac Odeyemi, Wen-Hung Chen, Dennis A Revicki. Content validity and testretest reliability of patient perception of intensity of urgency scale (PPIUS) for overactive bladder. BMC Urology 2012; 12:26. http://www. biomedcentral.com/1471-2490/12/26

17. Song M, Chun JY, Yoo DS, Han JY, Choo MS. Correlation of Overactive Bladder Symptom Score, the Voiding diary and Urodynamic parameters in patients with Overactive Bladder Syndrome. Low Urin Tract Symptoms 2014; 6(3): 180-4.PMID: 26663602

18. Blaivas JG, Tsui JF, Mekel G, Benedon MS, Li B, Friedmn FM et al. Validation of Lower Urinary Tract Symptoms Score. The Can J Urol 2015; 22(5):79528.PMID: 26432964.

19. Wang JY, Liao L, Liu M, Sumarsono B, Cong M. Epidemiology of lower urinary tract symptoms in a cross-sectional, population-based study.The status in China. Medicine (Baltimore) 2018; 97(34): e11554.PMID: 30142751 